\title{
\begin{tabular}{l|l} 
Mibraries & DSpace@MIT
\end{tabular}
}

\author{
MIT Open Access Articles
}

Lessons learned from longitudinal modeling of mobile-equipped visitors in a complex museum

The MIT Faculty has made this article openly available. Please share how this access benefits you. Your story matters.

As Published: https://doi.org/10.1007/s00521-019-04099-8

Publisher: Springer London

Persistent URL: https://hdl.handle.net/1721.1/131788

Version: Author's final manuscript: final author's manuscript post peer review, without publisher's formatting or copy editing

Terms of Use: Article is made available in accordance with the publisher's policy and may be subject to US copyright law. Please refer to the publisher's site for terms of use. 


\section{Lessons learned from longitudinal modeling of mobile-equipped visitors in a complex museum}

Cite this article as: Francesco Piccialli, Yuji Yoshimura, Paolo Benedusi, Carlo Ratti and Salvatore Cuomo, Lessons learned from longitudinal modeling of mobile-equipped visitors in a complex museum, Neural Computing and Applications https://doi.org/10.1007/s00521019-04099-8

This Author Accepted Manuscript is a PDF file of an unedited peer-reviewed manuscript that has been accepted for publication but has not been copyedited or corrected. The official version of record that is published in the journal is kept up to date and so may therefore differ from this version.

Terms of use and reuse: academic research for non-commercial purposes, see here for full terms. https://www.springer.com/aam-terms-v1 
Noname manuscript No.

(will be inserted by the editor)

\title{
Lessons learned from longitudinal modeling of mobile-equipped visitors in a complex museum
}

\author{
Francesco Piccialli · Yuji Yoshimura • \\ Paolo Benedusi · Carlo Ratti · Salvatore \\ Cuomo
}

Received: date / Accepted: date

\begin{abstract}
Cultural sites are evolving towards Smart Environments, including the notion of hyper-connected museums. In this context, stakeholders of cultural assets need more advanced and comprehensive ICT systems for monitoring and modelling visitors behaviors. In this paper we discuss the results of a longitudinal research study embracing multiple seasons, in a complex cultural structure including outdoor and indoor attractions, multiple floors and multiple routes for visitors. Here interactive mobile devices were used for both offering multi-medial context-aware assistance to visitors and monitoring services to museum stakeholders. We deeply analyzed the data using an unsupervised classification approach, obtaining a model where the number of distinct user profiles and the number of features were considered not trivial as well as not too complex for museum stakeholders. We observed that some optimistic expectations about visitor performances were only partially met, devising possible explanations in terms of the different user profiles and
\end{abstract}

Francesco Piccialli

University of Naples Federico II, Department of Electrical Engineering and Information Technology

Via Claudio 21, 80125, Naples, Italy

E-mail: francesco.piccialli@unina.it

Yuji Yoshimura and Carlo Ratti

SENSEable City Laboratory, Massachusetts Institute of Technology - MIT,

77 Massachusetts Avenue, Cambridge, MA 02139, USA

E-mail: \{yyoshi,ratti\}@mit.edu

Paolo Benedusi

Databooz Italia s.r.l.

Centro Direzionale Via G.Porzio 4, 80143, Naples, Italy

E-mail: paolo.benedusi@databooz.com

Salvatore Cuomo

University of Naples Federico II, Department of Mathematics and Applications "Renato Caccioppoli"

Via Cinthia, 80126, Naples, Italy

E-mail: salvatore.cuomo@unina.it 
features of the model. Finally, we also compared some outcomes from our interactive system with those obtained in another complex cultural structure using a non-invasive monitoring system.

Keywords User behaviours · User modeling • Unsupervised Classification . Data Analysis · Data Mining · Internet of Things

\section{Introduction}

Visitors of cultural sites represent a peculiar class of users, which pose multiple challenges for effective behavior modeling: this is becoming more and more important for both traditional museums and for technologically aided / augmented versions of them. In spite of the widespread availability of any kind of fixed and mobile devices, a recent survey on international experiences of museums observatories [1] revealed that systematic data collection is almost exclusively based on ticketing and questionnaires. These entail many limitations, including small size of samples, reluctance of some people to answering, difficulties in ensuring proper randomization, time and cost of interviews, and low frequency of global investigations and analyses (i.e. 2 times per year) [1]. Indeed, such questionnaires include information which can be gathered or inferred, in great part, using technological devices: favourite hours and length of the visit, activities performed during the visit, preferred information channels used, types of materials and information contents which were read or listened. For this purpose, non-invasive systems exploit devices which can track the presence and movements of visitors without any form of pre-registration or explicit provisioning of devices for identification and interaction. As an alternative, interactive systems offer multiple types of sensory experiences and services to the users, using devices which also monitor and save information on user positions, actions and timings. Each kind of system has its own specific merits and limitations, while both allow for continuous, massive, automated gathering and monitoring of evidences, as well as for very frequent analysis (even real-time) and longitudinal studies. In this paper, we present a comprehensive user modeling method which can embrace non-invasive, interactive, and even mixed scenarios, where information gathered from multiple types of passive and interactive devices can be combined. We experimented this method in a cultural site representing multiple options, opportunities and complexity factors which can influence and shape user behaviours: these include structural complexity (number of floors, rooms, open and closed spaces, different routes and means for physical movements such as scales or lift), richness /diversity of cultural attractions, and technological sophistication of the multi-medial interactive devices offered to the visitors. At the same time, we strove for a model which could be easy to understand and use by museum stakeholders and, more in general, promoters of cultural heritage resources, in order to support decisions and check the effectiveness of initiatives geared towards the improvement of user engagement and the evolution of cultural offerings. The rest of the paper is organized as follows: section 2 discusses a summary 
of related work, section 3 describes the technology used for data collection and modeling, section 4 and 5 present a methodology based on unsupervised techniques and related experimental results, while section 6 highlights and discuss the main lessons learned from this study, and section 7 provide some conclusions and perspectives for further research.

\section{Background and Related Work}

Traditionally visitor studies in museum have been conducted to analyze visitors behaviour and their spatial use, based on the interview and observation at most cases [16]. They largely rely on the paper-and-pencil method, "timing and tracking" [18]. The collected information is mapped and examined to make a basic knowledge for the management (e.g., the number of visitors, their visiting patterns), including to measure attracting power, where attracts the visitors and holding power, which is the length of time spent looking. Based on manually collected relatively small-scale samples, it was proposed to classify the visiting style of visitors $[17,22,24]$. The recently appearing emerging technologies revolutionized the way of collecting the behavioral data in museums and enables us to collect more finer granular space and time resolution [19]. They are, for example, RFIDs [32] , Bluetooth [26], or the combination of other wearable devices (for example, see [20]). The collected data are used to classify visitors into the pre-established visiting types (i.e., the busy, selective and greedy) by their path and length of stops [29], to predict the estimated viewing times and the exhibited place to be interested for a visitor, based on their previous location and viewed time [30], and to validate the previously made classifications by the quantitative data $[31,36]$. They also enable us to compare mathematical simulations of visit styles [36] with the impacts of multi-medial location-aware guides, showing that visitors using such guides on their mobile devices tend to extend the duration of their visits, while reducing the social interactions among members of the same visitor group [35]. In this perspective, authors in [23] propose an interesting study on how visitors distribute their time across artworks in a real case study (the CoBrA Museum of Modem Art); the limited number of considered volunteered visitors (180) limits the overall considerations and results they propose. However, the gathered datasets have often been still small-scale samples rather than longitudinal neither dynamic nor fine grained. $[26,14]$ collected the large-scale sample in the large-scale art museum (i.e., Louvre museum), showing the underlying patterns of visitors' behaviors in terms of the path sequence and their length of stay in the museum, but they did not classify the visiting style in terms of visitors' attributions nor apply the clustering approach for that purpose.

At the tecnological level, in the last years a handful of different types of devices were experimented for detecting and tracking presence, flows and other behaviours of visitors, including RFIDs, videocameas, sensors placed at entry and exit points of rooms, microphones, personal mobile devices, smart glasses and other wearable devices [33]. This made it possible to compare mathemat- 


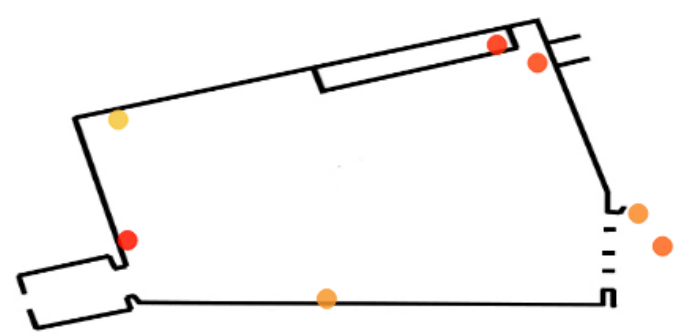

The Maschio Angioino Castle

and

the Civic Museum of Castelnuovo

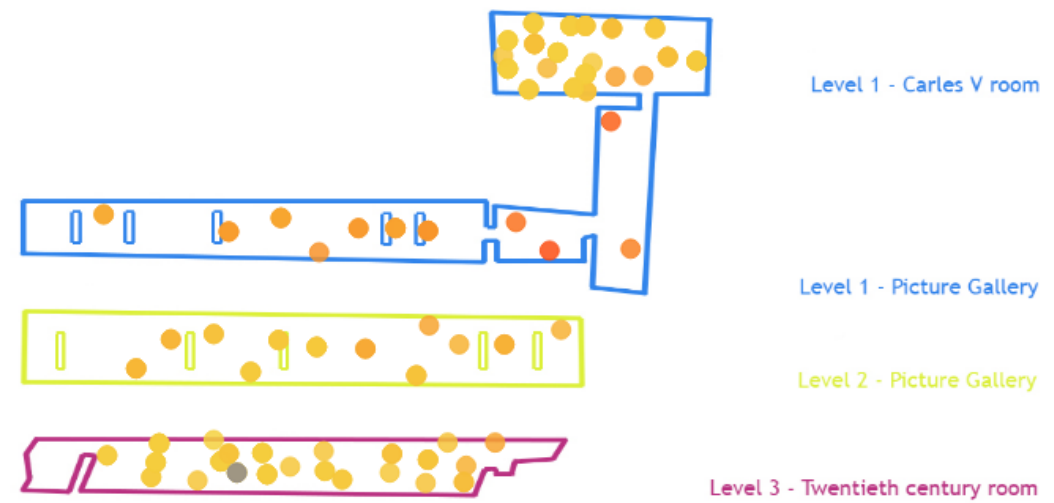

Level 0 - The Courtyard

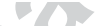

Fig. 1: The Maschio Angioino castle map: the bubbles represent the artworks position.

ical simulations of visit styles [36] with the impacts of multi-medial locationaware guides, showing that visitors using such guides on their mobile devices tend to extend the duration of their visits, while reducing the social interactions among members of the same visitor group [35]. Furthermore, authors in [21] discuss a theoretical approach and methodology to eye-tracking research and museum interactive learning experiences. Particularly promising appear the non-invasive systems, which detect and follow the Media-Access-Control (MAC) addresses of personal Wi-Fi and /or Bluetooth devices commonly used by visitors, including smartphones, earphones, smart swatches, bracelets and similar electronic tags $[34,14]$. This paper proposes an unsupervised clustering approach to the large-scale dataset of visitors' behaviours in a complex museum environment. In the rest of the paper we will show the feasibility of the proposed classification approach for visitors' visiting styles.

\section{Data Collection and Modelling}

In our experiments, we monitored a museum located inside a castle named Castel Nuovo (also known as Maschio Angioino), where artworks are distributed into multiple rooms at multiple levels or floors (see Fig. 1).

From the Courtyard, visitors can reach the first floor by either climbing the stairs or taking the lift, which also provides access to the upper floors. Each 
Table 1: The list of the artwork-related commands available on the mobile application.

\begin{tabular}{|l|l|l|}
\hline Type & Command & Parameter values \\
\hline artwork & artwork_selected & Artwork title/id \\
\hline audio track & play_button_playing & false, true \\
\hline audio track & seektrack_at & position of slider in the audio file \\
\hline text guide & text_button & invisible, visible \\
\hline photo & nextpic_photo & n. of photo/picture in the list \\
\hline photo & prevpic_photo & n. of photo/picture in the list \\
\hline
\end{tabular}

bubble represents an artwork (or group of artworks) for which our smart museum equipment collected statistics: in particular, colour saturation and divergence represent a scale of temperatures proportional to the number of visitors. The museum environment is equipped with IoT Beacon sensors; each sensor is placed very close to an artwork (or a group of artworks) and it emits a Bluetooth Low Energy signal. A mobile application named @art, deployed on many tablets, scans the environment locating the Beacon sensors in its surrounding area.

Such tablets (see Fig. 2) provide two kind of services in parallel: multi-medial assistance to visitors in multiple languages, and monitoring for museum stakeholders. The @art app is location-aware, in that it identifies the beacons in its neighborhoods, and each beacon has a unique identifier and local coordinates, which are whole numbers relative to the museum map. Based on these coordinates and a proximity algorithm, the APP determines the subset of artworks which are closer to the visitor. Then a list of artwork icons and names appears is shown on the tablet screen, and when the visitor selects one item, the APP proposes a set of item-specific multi-medial resources: the first picture of a gallery, a short text, and an audio file which starts playing by default. The user can change the default language, navigate the picture gallery, make the text invisible or visible, and use the most common commands of audio players, i.e. stop, restart, and move back and forth the slider of the audio track. Each visitor may select the same artwork multiple times, either in sequence or by returning to the same artwork after having selected other ones. The app saves records of all user actions in a $\log$ file, of which Fig. 3 provides an excerpt, while Table 1 provides some details on the artwork-related command codes. At the beginning of each visit a new log file is issued, while at the end it is transferred from the tablet to a central file store, where each visit is uniquely identified by a progressive, anonymous number. For the objectives of our study, we analyzed only artwork-related commands in the logs (Table 1), calculating statistics at two basic level of aggregation: single artwork selection event, and entire visit of each person (Table 2)

\section{Methodology}

In order to detect and characterize different visitor profiles, we analyzed the collected behaviors by using an unsupervised approach which is composed of 


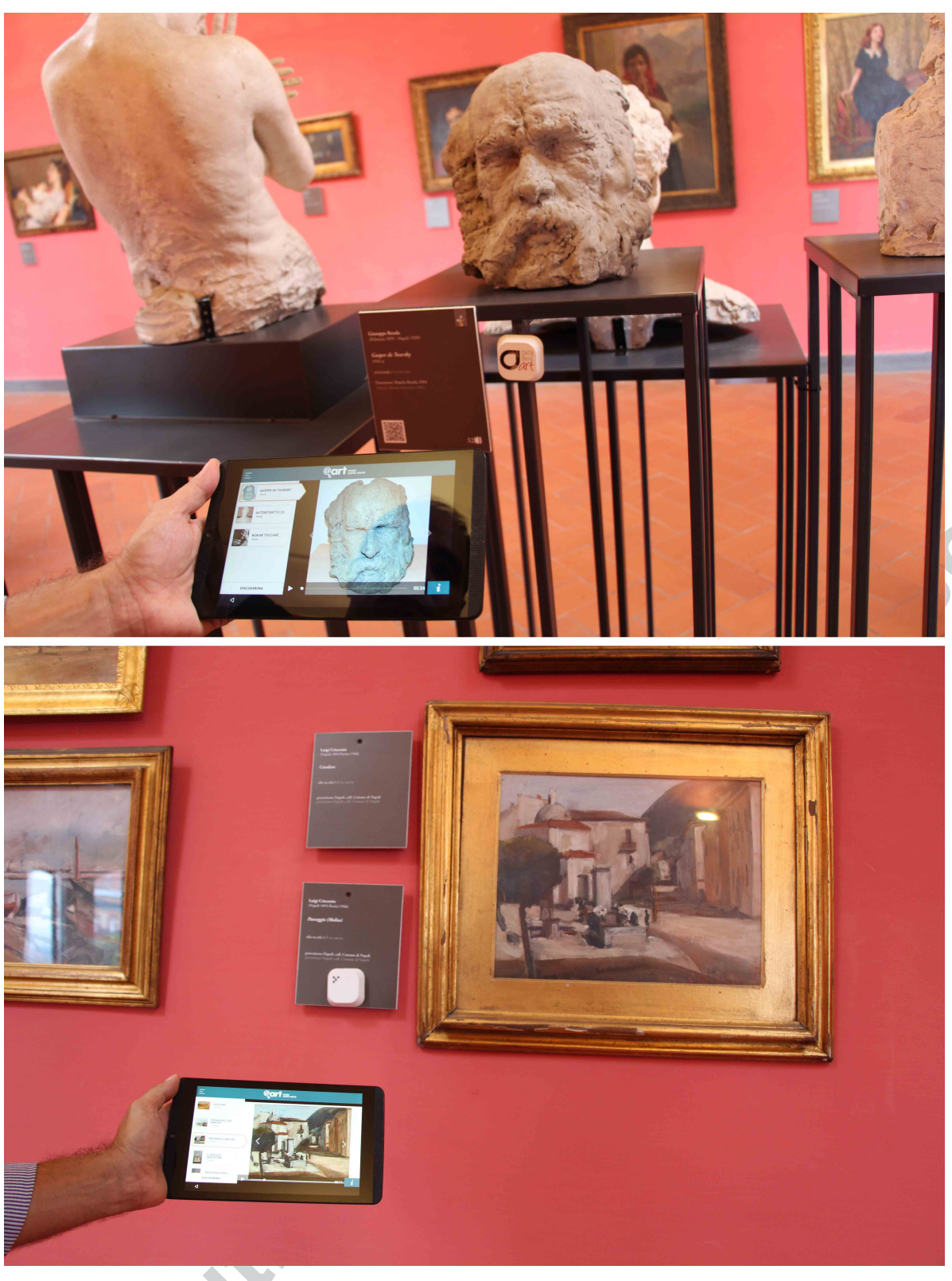

Fig. 2: Some pictures of the @art mobile application and the deployed Bluetooth Beacon sensors within the Maschio Angioino castle. 
2017/09/09 14.45.50 :kind: languageButton :details: ita

2017/09/09 14.45.54 :kind: Antonio Toscano a Vigliena :details: artwork selected

2017/09/09 14.46.11 :kind: Sala Carlo V. La donazione Jerace... : details's: artwork selected

2017/09/09 14.46.55 :kind: Sala Carlo V. La donazione Jerace... : details: seektrack_at: 8489

$2017 / 09 / 0914.46 .55$ :kind: Sala Carlo V. La donazione Jerace... : details: prevpic photo n.1

$2017 / 09 / 0914.46 .56$ :kind: Sala Carlo V. La donazione Jerace... : :details: seektrack at: 7397

$2017 / 09 / 0914.46 .56$ :kind: Sala Carlo V. La donazione Jerace... : details: nextpic_photo n.0

2017/09/09 14.47.29 :kind: Arco di Trionfo di Alfonso... : details: artwork selected

Fig. 3. An excerpt of a log file generated by the deployed system during a visit. Each line corresponds to a visitor action with an associated timestamp.

Table 2: A summary of the individual visit analyzed variables.

\begin{tabular}{|c|c|}
\hline Field & Content \\
\hline LFilenum & Numeric identifier of the individual visit log. \\
\hline LANG & Favourite language chosen in the tablet \\
\hline mintimeArtw & Minimum timestamp of artwork selection in the entire visit \\
\hline maxtimelog & timestamp of the last action recorded in the visit log \\
\hline elapsed & $\begin{array}{l}\text { Time elapsed from the first artwork selection } \\
\text { to the end of the tablet-based visit, measured in minutes }\end{array}$ \\
\hline nartw & Distinct count of artworks visited \\
\hline nactartw & $\begin{array}{l}\text { Number of tablet-based actions performed } \\
\text { by the visitor on artworks }\end{array}$ \\
\hline nfloors & $\begin{array}{l}\text { Distinct count of floors / levels of the building } \\
\text { where at least } 1 \text { artwork was visited using the tablet }\end{array}$ \\
\hline maxfloor & Maximum floor (numeric id) visited \\
\hline minfloor & Minimum floor (numeric id) visited \\
\hline nfullaudio & $\begin{array}{l}\text { Distinct count of artworks whose } \\
\text { audio files were played in full by the visitor }\end{array}$ \\
\hline nactaudio_up & $\begin{array}{l}\text { n. of actions which explicitly keep active } \\
\text { the audio track (seektrack_at, play_button_playing=true) }\end{array}$ \\
\hline nactaudio_stop & $\begin{array}{l}\text { n. of actions which interrupt listening of } \\
\text { the audio track (play_button_playing=false) }\end{array}$ \\
\hline Audioinfull & $\begin{array}{l}\text { Binary flag; } 1=\text { the audio track of } \\
\text { the selected artwork was played in full }\end{array}$ \\
\hline nactphoto & n. of actions on photos/pictures (nextpic_photo, prevpic_photo) \\
\hline nacttext_visible & n. of actions with text_button $=$ visible \\
\hline nacttext_invisible & n. of actions with text_button = invisible \\
\hline
\end{tabular}

three steps: (i) a data value standardization process, (ii) a Principal Component Analysis (PCA) [4] and (iii) a k-means clustering algorithm [5]. For what concern the step (i), in order to achieve a standardization of all potential features in the collected behavioral data (see Table 2), we mapped the values to fit the interval $[0,1]$ by using a simple formula:

$$
x \rightarrow x^{\prime}=\frac{\left|x-x_{\max }\right|}{\left|x_{\max }-x_{\min }\right|}
$$

where $x_{\max }$ and $x_{\min }$ are the maximum and the minimum value of, respectively. Then, regarding the step (ii), we executed the PCA algorithm on these data. As we can observe from the results in Fig. 4, only six features contributed more than the $10 \%$ to the composition of the first Principal Component. Starting from this observation, we considered only those six features as input for 


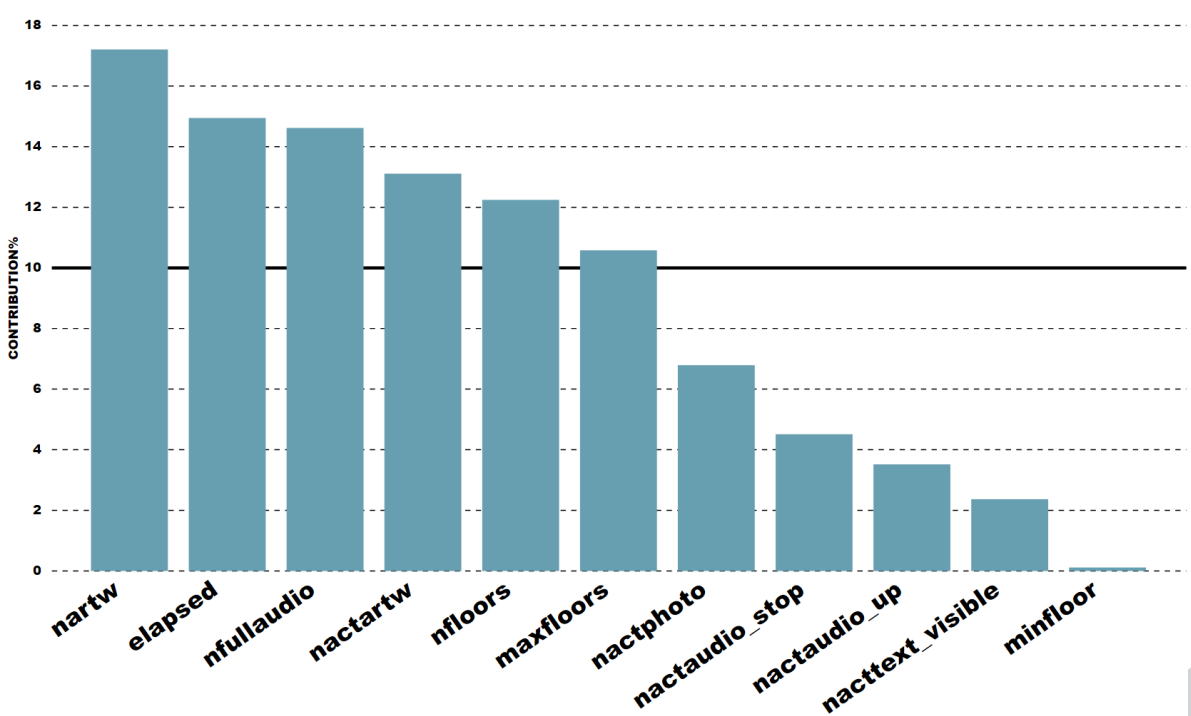

Fig. 4: The Principal Component Analysis results.

the next step. In details, the six features showing an adequate predictive potential are: nartw, elapsed, nfullaudio, nactartw, nfloors, and maxfloors. All the experiment where conducted on the $\mathrm{R}$ framework [6].

Finally, focusing our attention on the step (iii), we had to consider some key aspects related the to the possible optimal selection of the $\mathrm{k}$ value, as input for the k-means clustering algorithm. As it is well known, its is still an open research problem, and the notion of optimal should be re-stated as more suitable or recommended with respect to the research domain, the available data and the main goals of the Data Analysis. For example, an evaluation function $\mathrm{f}(\mathrm{K})$ was proposed by the authors in [7] to support the selection of the $\mathrm{k}$ value; unfortunately this approach entailed several onerous re-calculations of a set of equations to find the $\mathrm{k}$ value with an optimal evaluation. In our case, the $\mathrm{k}$ selection problem was supported by an extension of the $\mathrm{R}$ framework named NBclust package [8]. This useful package, given the dataset as input, provides the automated calculation of many indexes used for determining the number of clusters (the $\mathrm{k}$ value) to be selected as input for the k-means algorithm.

In order to exploit these capabilities, and observing the strategy in [7], we considered to balance the cost and benefits of the $\mathrm{k}$ selection strategy depending on the observations level of details; in particular, a dataset with $\mathrm{n}$ objects could be grouped into any number of clusters between 1 and n, which would correspond to the lowest and the highest levels of detail respectively. By specifying different values of $\mathrm{k}$, it is possible to compare and assess the results in terms of relationships among features and their variability at the intra-cluster and extra-cluster levels. Furthermore, by defining $x_{i}$ as the (p-dimensional) vector 
of objects of the cluster $C_{k}$ and $\overline{x_{k}}$ its centroid, the within-group dispersion matrix can be defined as follows:

$$
W_{q}=\sum_{\mathrm{k}=1}^{q} \sum_{i \in C_{k}}\left(x_{i}-\bar{x}_{k}\right)^{T}\left(x_{i}-\bar{x}_{k}\right)
$$

where $q \in(1, \ldots, n-2)$ and $n$ is the number of observation in the data matrix.

In our case we have selected $p=6$, since each object represents an individual visitor considering the 6 features output of the step (ii), while $n$ is the total number of visitors stored in the dataset. By using the NBclust package, we examined many indexes based on the $W_{q}$ matrix, focusing our attention on the following ones: TraceW, Hartigan, Duda, Pseudo $-T^{2}$ and Beale, which are defined as follows:

$$
\operatorname{Trace} W=\operatorname{trace}(W)
$$

where the trace of an n-by-n square matrix $\mathrm{W}$ is defined to be the sum of the elements on the main diagonal. This iterative approach relies on increasing values of $q$, until the difference between the results of two successive iterations maximizes its value, and yields the recommended value of $\mathrm{k}$.

$$
\text { hartigan }=\left(\frac{\operatorname{trace}\left(W_{q}\right)}{\operatorname{trace}\left(W_{q+1}\right)}-1\right)(n-q-1)
$$

where the optimal number of clusters is the value of $q$ which maximizes the hartigan index;

$$
d u d a=\frac{W_{l}+W_{k}}{W_{m}}
$$

where $\mathrm{k}, \mathrm{l}$ and $\mathrm{m}$ are such that: $C_{m}=C_{k} \cup C_{l}$ and the optimal number of clusters is the minimum $q$ for which:

$$
d u d a=1-\frac{2}{\pi \mathrm{p}}-z \sqrt{\frac{2\left(1-\frac{8}{\pi \mathrm{p}^{2}}\right)}{n_{m} p}}
$$

where $z$ is the standard normal score, and the corresponding value of duda is named critValueduda; we tested this criterion using various choices for $z$, obtaining the best result from NBClust when the value is set to 3.20. Then we used the critValueduda for the optimization of the Pseudo $-T^{2}$ index:

$$
\text { Pseudo }-T^{2}=\frac{B_{k l}}{\frac{W_{k}+W_{l}}{n_{k}+n_{l}-2}}
$$

where $B_{k l}=W_{m}-W_{k}-W_{l}$ and the optimal number of clusters is the smallest $q$ for which: 


$$
\begin{gathered}
\text { Pseudo }-T^{2} \leq\left(\frac{1-\text { criticValueDuda }}{\text { criticValueDuda }}\right)\left(n_{k}+n_{l}-2\right) \\
\text { beale }=F \equiv \frac{\frac{W_{m}-\left(W_{k}+W_{l}\right)}{W_{k}+W_{l}}}{\left(\frac{n_{m}-1}{n_{m}-2}\right) 2^{\frac{2}{p}}-1}
\end{gathered}
$$

Where $\mathrm{F}$ stands for a statistical test, in which the statistic has an Fdistribution under the null hypothesis. The criterion consists in verifying whether an increase ok the $\mathrm{k}$ value (i.e. from $\mathrm{k}-1$ to $\mathrm{k}$ ) entails a significant reduction in the internal deviancy of groups, with relevant distances among the group centroids. This iterative approach is based on increasing the values of $\mathrm{k}$. At each iteration it calculates a critical value with a Fisher distribution having two degrees of freedom $F p,(N m-2) p$; the minimum value of $F$ for which this critical value is greater than a predefined parameter (alphaBeale) determines the recommended value for $\mathrm{k}$. On our case, we adopted the default parameter value $(0.10)$.

To further assess the $\mathrm{k}$ value selection, we also considered the Marriot and Scott indexes [13], both based on the Sum-of Squares and CrossProducts (SSCP) matrix. The SSCP matrix consist of dependent variable sum of squares or variances along the diagonal of the matrix and covariances (cross-products) on the off-diagonal elements that represent the common variance shared between two variables [15]. In details, regarding the SSCP matrix, we have:

- the total sample matrix is: $T=X^{T} X$;

- if $\bar{X}=\left(Z^{T} Z\right)^{-1}$, and $Z$ is a cluster indicator matrix $(n \times q)$ with element :

$$
z_{i k}= \begin{cases}1 & i \in C_{k} \\ 0 & \text { altrimenti }\end{cases}
$$

then the between-cluster matrix is $B=\overline{X^{T}} Z^{T} Z \bar{X}$;

- finally, the within-cluster matrix is: $W=T-B$

From this considerations, the indexes can be defined as follows:

$$
\text { marriot }=k^{2}|W|
$$

This approach aims to evaluate up to which extent it is convenient to increase the number of clusters, in terms of decreasing intra-cluster variability and increasing inter-cluster distance. This iterative approach relies on increasing values of $\mathrm{k}$. At each iteration, it performs a k-means clustering and calculates the difference between two consecutive values of the marriot index; when this difference reaches a maximum, the algorithm yields the recommended value of $\mathrm{k}$. 
Table 3: The measured K-means indexes and the suggested number of clusters.

\begin{tabular}{|l|c|c|c|c|c|c|c|}
\hline & TraceW & Hartigan & Duda & Scott & Marriot & Pseudo $-T^{2}$ & Beale \\
\hline $\begin{array}{l}N^{\circ} \text { of } \\
\text { Clusters }\end{array}$ & 5 & 5 & 5 & 5 & 5 & 5 & 5 \\
\hline $\begin{array}{l}\text { Index } \\
\text { value }\end{array}$ & 88,994 & 2970,232 & 1,032 & 13507,48 & 574,4661 & $-34,0339$ & $-0,1192$ \\
\hline
\end{tabular}

$$
\operatorname{scott}=n * \log (|T| /|W|)
$$

The algorithm iterates on increasing values of $\mathrm{k}$; at each iteration, it calculates the difference between two consecutive values of the scott index; when this difference reaches a maximum, the algorithm yields the recommended value of $\mathrm{k}$.

The results obtained by executing the NBclust package, related to the value calculation of the considered indexes, suggest us a $\mathrm{k}$ value selection as summarized in Table 3.

manageable to museum stakeholders. The suggested $\mathrm{k}$ value (number of clusters) can be considered as suitable with our aim to build a model conceived to be not simplistic (as it would come from other kinds of indexes suggesting $\mathrm{k}=2$ ) as well as not too complex, and dealing with 5 clusters of visitors appearing to be manageable for the museum stakeholders.

\section{Results}

In this section we summarize the basic characteristics of the collected data and then we present the final results of clustering analysis with some considerations.

\subsection{Characteristics of the collected data}

In previous experimentations we offered a promotional version of the APP, which anyone could download for free into their own smartphones; in addition, we offered to visitors a limited number of complimentary APP-equipped tablets. However, these experiences were concentrated in isolated events, such as an exhibition located in a single floor of a monumental building [3], which was monitored for a limited time period. Subsequently, various improvements and simplifications were introduced in the @ Art 2.0 version, and we decided to experiment a systematic / routine offer of APP-equipped tablets at the entrance of a Museum, which visitors could rent paying a small charge in addition to the museum ticket. Visitors who pay two fees represent the self-selection a special kind of population, which theoretically should be very motivated and interested in cultural heritage and related technological aids. In practice, is was necessary to check and measure to which extent these expectations were 
Table 4: The five clusters $(\mathrm{k}=5)$ and the related features values.

\begin{tabular}{|r|r|r|r|r|r|r|r|r|}
\hline cluster & maxfloor & nfloors & nartw & nfullaudio & nactartw & elapsed & population & \%pop \\
\hline 1 & 1,00 & 0,99 & 0,33 & 0,30 & 0,14 & 0,33 & 651 & $13,80 \%$ \\
\hline 2 & 0,02 & 0,00 & 0,01 & 0,01 & 0,03 & 0,07 & 201 & $4,26 \%$ \\
\hline 3 & 1,00 & 0,90 & 0,13 & 0,10 & 0,07 & 0,22 & 1350 & $28,61 \%$ \\
\hline 4 & 0,33 & 0,33 & 0,09 & 0,07 & 0,07 & 0,17 & 2081 & $44,10 \%$ \\
\hline 5 & 0,70 & 0,62 & 0,10 & 0,09 & 0,07 & 0,20 & 436 & $9,24 \%$ \\
\hline Total & & & & & & & $\mathbf{4 7 1 9}$ & $\mathbf{1 0 0 , 0 \%}$ \\
\hline
\end{tabular}

Table 5: An analysis of the features percentiles.

\begin{tabular}{|l|l|l|}
\hline & avg\% & 90pct\% \\
\hline nfloors & 0,60 & 1,00 \\
\hline nfullaudio & 0,11 & 0,25 \\
\hline elapsed & 0,21 & 0,33 \\
\hline nacartw & 0,08 & 0,15 \\
\hline
\end{tabular}

met, possibly distinguishing whether the dominant interest was towards technology or art, or the combination of both. We thus performed a longitudinal study, analyzing data collected within a semester (May 16 th - October 31th 2017 , a period of time which spans over 3 seasons). The initial number of artworks selected for monitoring was 164 , but malfunctions of a beacon during the months reduced the beacon-monitored artworks to 160. In the following, visitors who rent and used the tablet are named T_visitors, or even visitors as a shorthand. Over the entire period, the number of T_visitors is 4719 , and coincides with the number of log files.

\subsection{Clustering results}

We executed a 5-means algorithm in $\mathrm{R}$ including the 6 features chosen with the PCA, obtaining the numeric cluster profiles shown in Table 4.

In order to facilitate interpretation and understanding of the numbers, we mapped them to nominal scales with common labels such as low, medium, high. We had to consider the fact that different features have different density distributions of values and outliers, so that the same numeric value may appears low in the context of one feature, and high in the context of another, as can be understood from the examples shown in Table 6 .

As the values in Table 4 were obtained by mapping the original values to the $[0,1]$ interval, in Table 5 we used the $\%$ symbol to emphasize that they represent percentages with respect to the original intervals of values, which have different orders of magnitudes and ranges for each feature. In the case of nfloors (with possible original values $1,2,3,4$ ), the value at the 90th percentile equals the standardized maximum (1.0), and it is quite far from the standardized average (0.60). On the contrary, in the case of elapsed (originally a continuum of values up to hundreds of minutes), the value at the 90th percentile (0.33) is very far from the standardized maximum (due to a 
Table 6: The Cluster-profile mappings with a nominal scale.

\begin{tabular}{|l|l|l|l|l|l|l|}
\hline cluster & $\begin{array}{c}\text { Distinct } \\
\text { Artworks } \\
\text { selected }\end{array}$ & $\begin{array}{c}\text { T-Actions } \\
\text { on } \\
\text { artworks }\end{array}$ & $\begin{array}{c}\text { Listening: } \\
\text { n. artworks } \\
\text { audio in full }\end{array}$ & $\begin{array}{c}\text { Time: } \\
\text { elapsed } \\
\text { in visit }\end{array}$ & $\begin{array}{c}\text { Space: } \\
\text { inter-floors } \\
\text { movement }\end{array}$ & $\begin{array}{c}\text { Profile } \\
\text { nickname }\end{array}$ \\
\hline 4 & low & low & low & medium & low & Moderate \\
\hline 3 & low & low & low & medium & high & Wanderer \\
\hline 1 & high & high & very high & High & very high & $\begin{array}{c}\text { Strongly } \\
\text { engaged }\end{array}$ \\
\hline 5 & low & low & low & medium & medium & Runner \\
\hline 2 & very low & very low & very low & very low & very low & Stranger \\
\hline
\end{tabular}

few rare outliers), while it is closer to the average (0.21). For such reasons, we can say that 0.33 has to be considered low in the context of maxfloors and nfloors, while it has to be considered high in the context of elapsed. Based on percentiles and averages, we defined different thresholds for each feature, and used them to map the numerical values to the labels of a common nominal scale, as shown in Table 6.

In this table, clusters are sorted by descending order of population, and the corresponding profile nicknames are used to synthetize the dominant aspects of each type of behavior as follows:

- Moderate visitors (cl.4) perform limited movements in space and limited T-based interactions with artworks, with average length of stay in the museum;

- Wanderers (cl.3) tend to extend their physical movements in most or all floors, performing limited T-based interactions, while spending more or less the same time of moderate visitors;

- Strongly engaged visitors (cl.1) tend to cover all floors and most artworks, exploiting in full the tablet functionalities, and devoting much time for such intense visit;

- Runners (cl.5) tend to cover a respectable number of floors, but only skimming a limited number of artworks, with corresponding limited T-based interactions

- Strangers (cl.2) seem some sort of outsiders, which behave as if they were out of place (what am I doing here?); they in fact tend to stay within the floor(s) at lowest levels of the museum, visiting few artworks in a short time.

\subsection{Insights in Clustering results}

The populations of clusters reported as percentages in Table 4 are referred to the total number of visitors in the entire period of monitoring; as our longitudinal study spanned over 5.5 months, we examined how the population of each cluster is distributed in each month. According to Fig. 5, the overall number of visits per month is quite variable, while the breakdown into cluster populations by month in Fig. 6 together with Fig. 7 reveal some regularities. 
n.Visits by Month
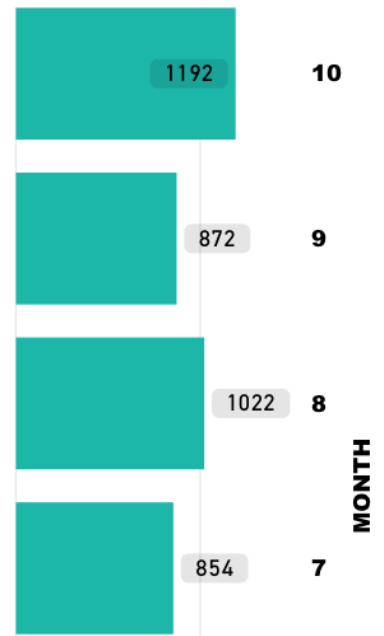

$854 \quad 7$
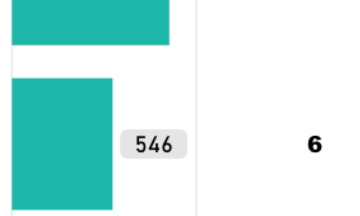

0
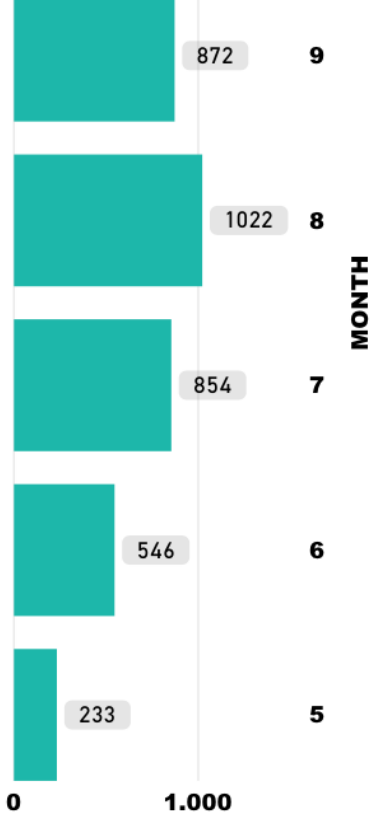

33

1.000

n.Visits

Fig. 5: The overall number of collected visits by month.

It is evident that the dominance relationships among cluster populations in the entire period (see Fig. 6) are generally preserved in each month, except for a small inversion between two clusters in October. The population of moderates (cl. 4) remains the highest in each month, followed by wanderers (cl. 3), strongly engaged(cl.1), runners(cl.5) and strangers(cl.2), respecting the same descending order of clusters in Table 4 until September.

However, as the overall population incurs relevant variations by month, we studied the stacked histogram in Fig. 7, where cluster populations are shown as percentages of the monthly totals: this allows to observe that the percentages of each cluster skip up and down in different months, as well as to observe that the differences between the relative ratios of cluster populations have small fluctuations. Only in October the population of strongly engaged visitors (cl.1) falls below that of runners(cl.5), but the order of magnitude of the corresponding variations is not relevant with respect to the fluctuations affecting each cluster in each month, thus an isolated inversion between two clusters having slight differences in their relative populations can be consid- 


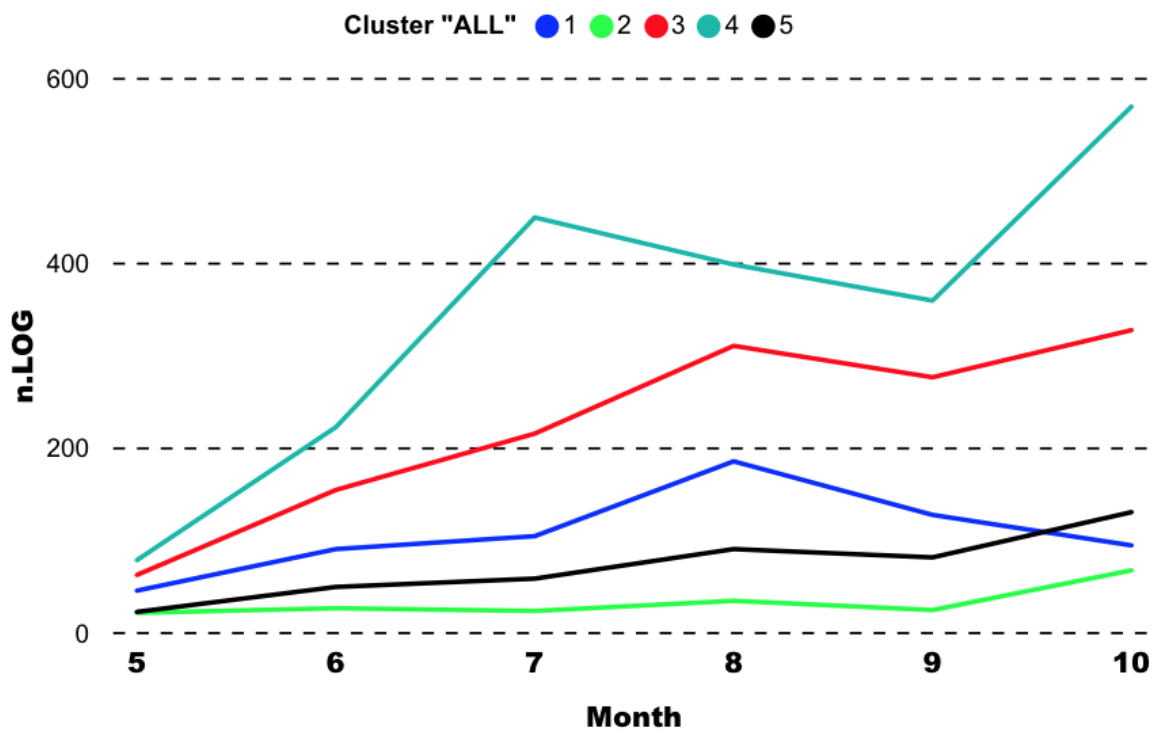

Fig. 6: The Cluster population size by month.

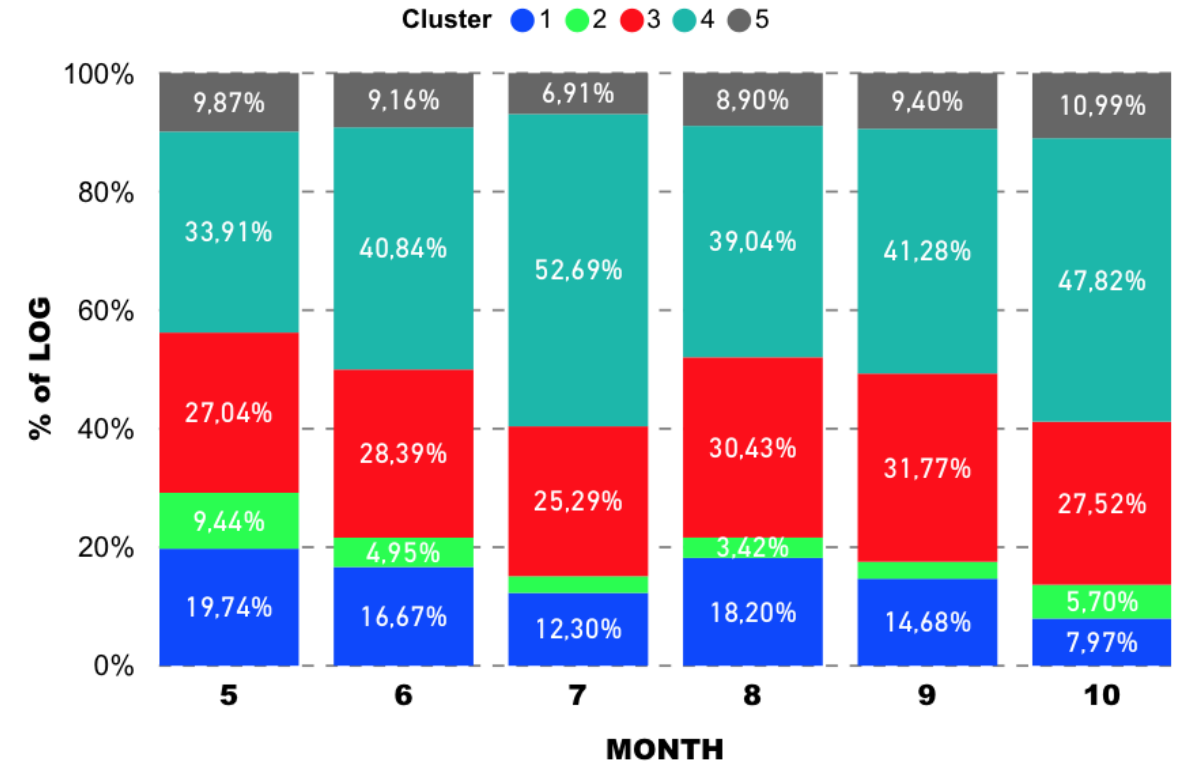

Fig. 7: The percentage of cluster population by month. 

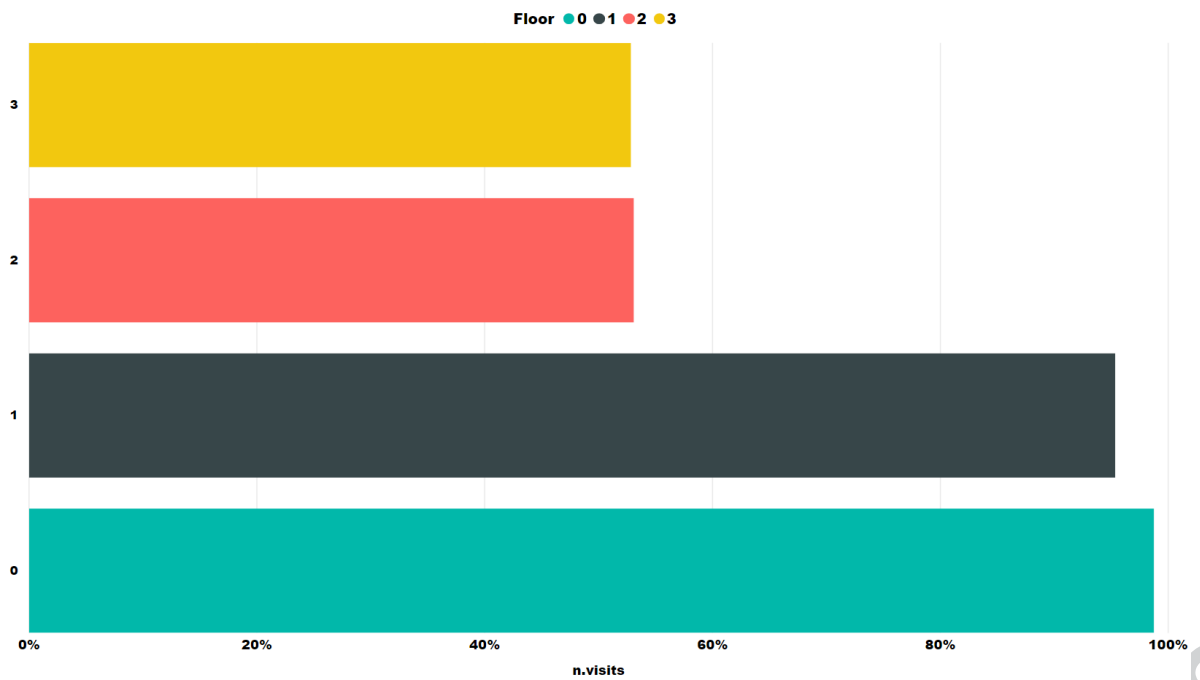

Fig. 8: The percentage of the number of visits by floor.

ered an occasional phenomenon. As clusters are positioned in a space with 6 dimensions, catching and assessing the relevance of specific aspects in visitor profiles is not immediate; for this reason, we examined projections onto some subspaces with few dimensions at a time. For aspects concerning the extent of physical movements in the museum, Fig. 8 demonstrates that the total number of visits per floor diminishes or remains stable as the floor level increases, while Fig. 9 reports the distribution of nfloors values in the population of each cluster.

It is evident that wanderers(cl.4) tend to visit 2 distinct floors, and they account for the majority of the total population. The value nfloors $=4$ occurs in almost all visitors of cluster 1(strongly engaged), and also in a great part of cluster 3(wanderers). A minor but still relevant part of the same cluster 3 has nfloors $=3$, and the same happens for the majority of visitors in cluster 5 (runners) and very few visitors in cluster 1 . The elapsed feature of our model roughly corresponds to the length of stay in other papers, where it is measured using different types of devices [14]. Investigations in this area include the possible influence of the museum entry times; for example, it seems reasonable to guess that visitors who enter in the museum in the early morning have (or estimate to have) much time to spend, thus expecting to observe higher lengths of stay than others, as well as higher propensity for tablet-based interactions. Similar guesses can hold for people initiating their visit just after lunch time, while people initiating late in the morning, or late in the afternoon are expected to have lower values in both elapsed and tablet-based interactions. In order to check such assumptions, we studied the diagrams reported in Fig. 10 and Fig. 11 . 
nfloors $\bullet 1 \bullet 2 \bullet 3 \bullet 4$

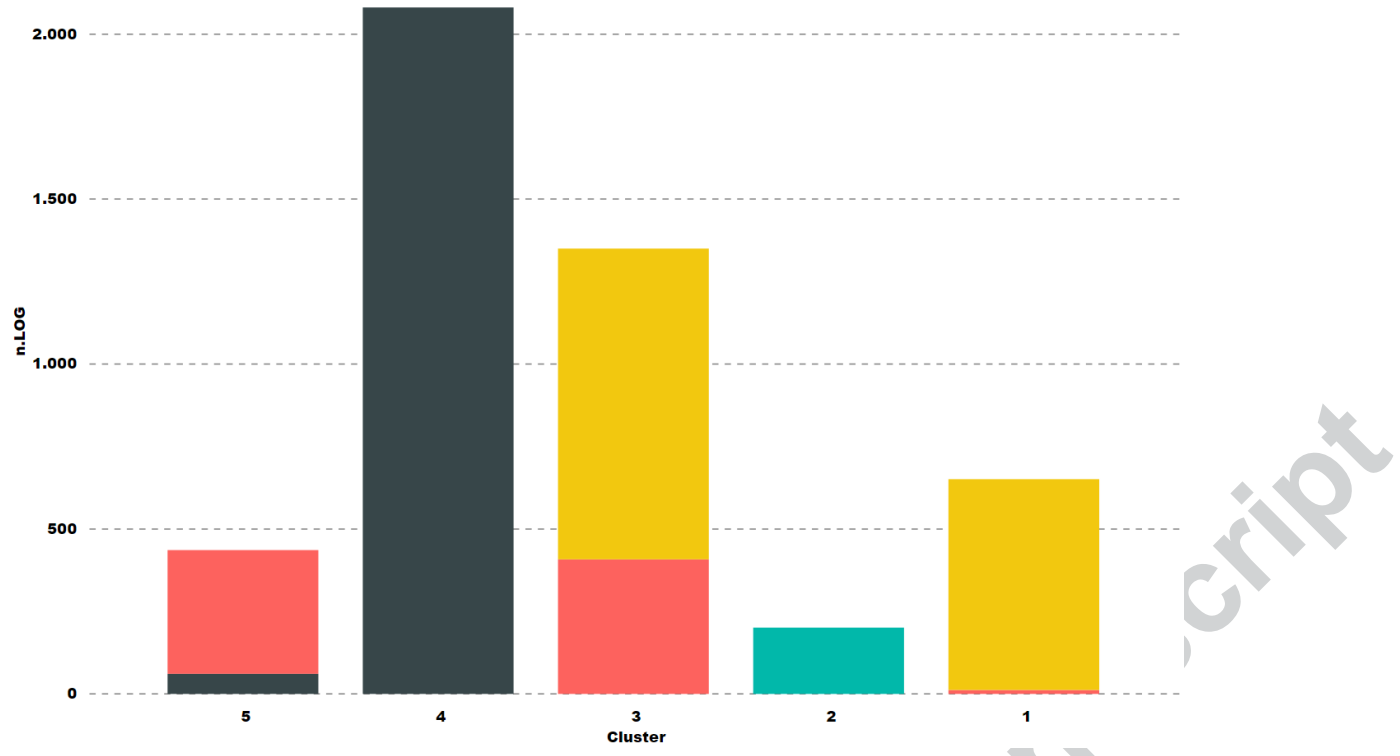

Fig. 9: The number of logged visits by cluster: breakdown of the number of distinct floors visited.

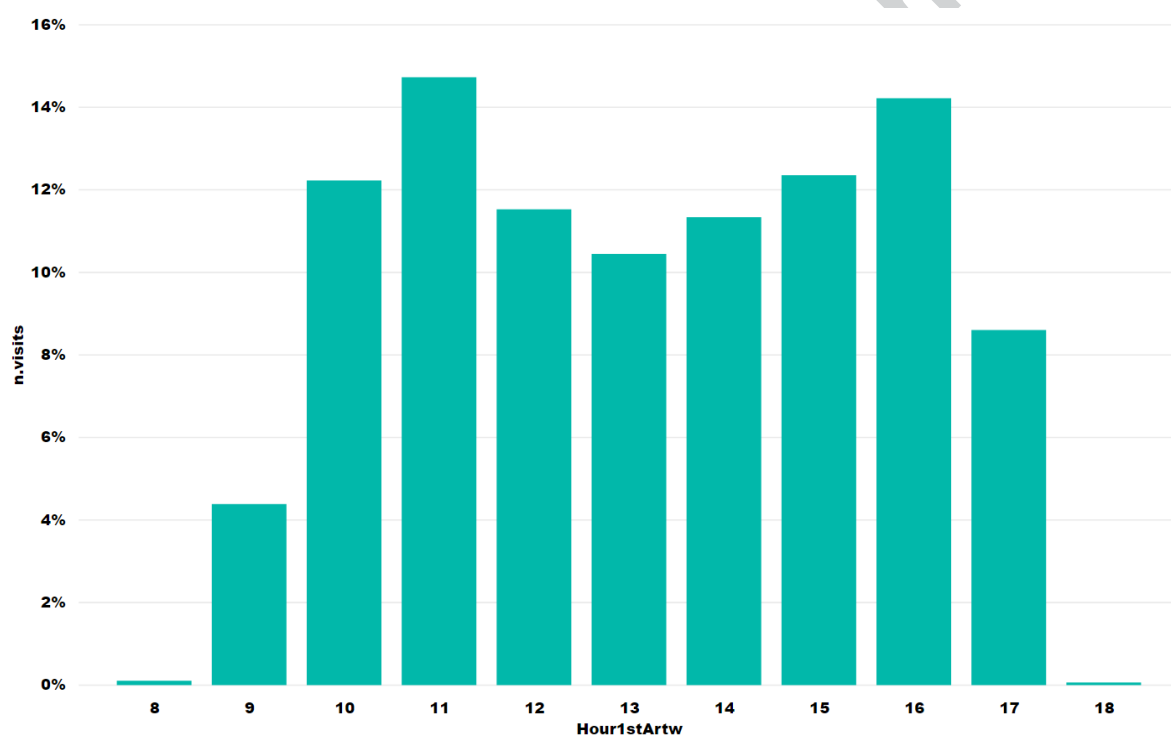

Fig. 10: The percentage of logged visits by entry hour (considering the time of the 1st artwork selection). 


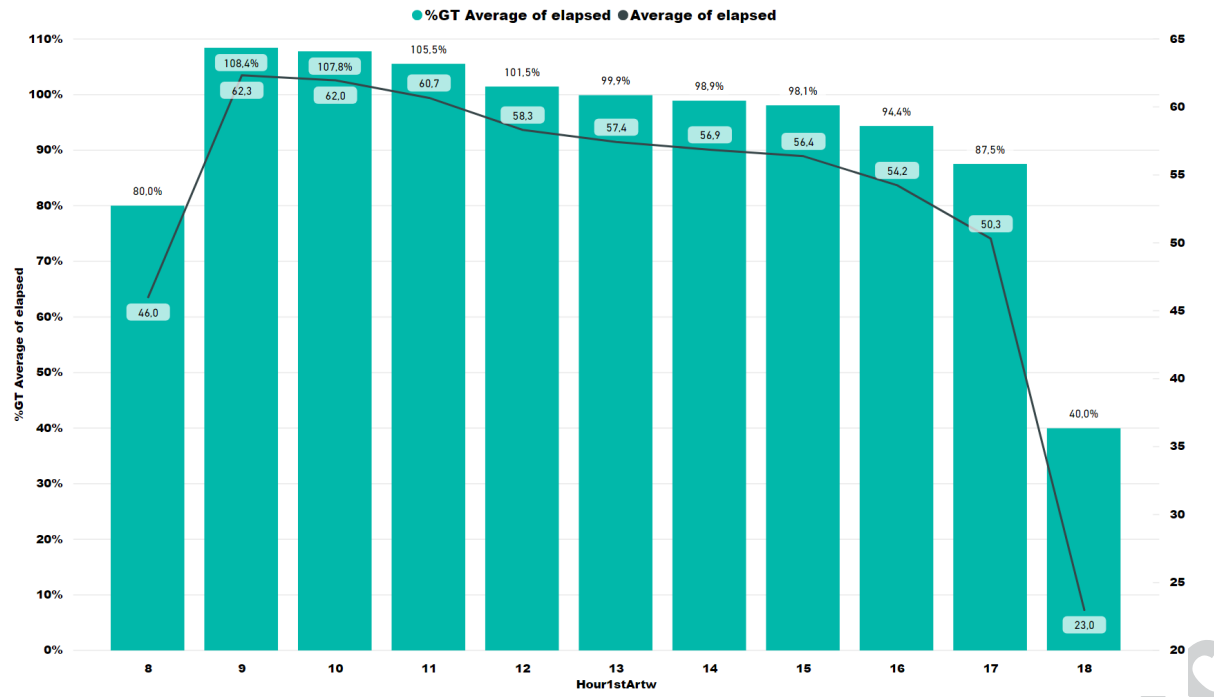

Fig. 11: The average visit elapsed times by entry hour.

In Fig. 10 the x-axis reports Hour1stArtw, which comes from the hour in the timestamp of the first T-based artwork selection in a visit, while the y-axis reports the number of visits which started in each hour band, as a percentage of the total population monitored in the entire period. We observe that there are up and down fluctuations, with peaks around 11:00 and 16:00, with a local minimum around lunch time (13:00), while only a minority of people initiated their visit in the last hour before the museums close time or just at the opening time. In Fig. 11 we focus on the average elapsed by entry hour, both in terms of absolute values and as percentage of the grand total average (i.e. the overall average on the total population in the entire period of monitoring).

It is evident that, starting from h.9:00, the average elapsed time tends to diminish as the entry hour increases; the slope is generally smooth, and becomes steep only when the entry time is within the last hour band. This pattern is consistent with the results of a previous study conducted at Louvre, a very complex and outstanding museum [14], where behaviors were detected using a non-invasive system which monitored the signals emitted by the personal bluetooth devices of the visitors. In that case, it was verified that the lengths of stay tend to decrease toward the closing hours of the museum; the earlier a visitor enters the museum, the longer that visitor tends to stay in the museum, so that the time visitors enter can be used to predict visitors lengths of stay in the museum. In our case, the interactive multi-medial assistance provided by tablets allowed to check and confirm such kind of results obtained by non-invasive devices, while providing additional value by distinguishing among different visitor profiles and many insights on how visitors spend their time. 


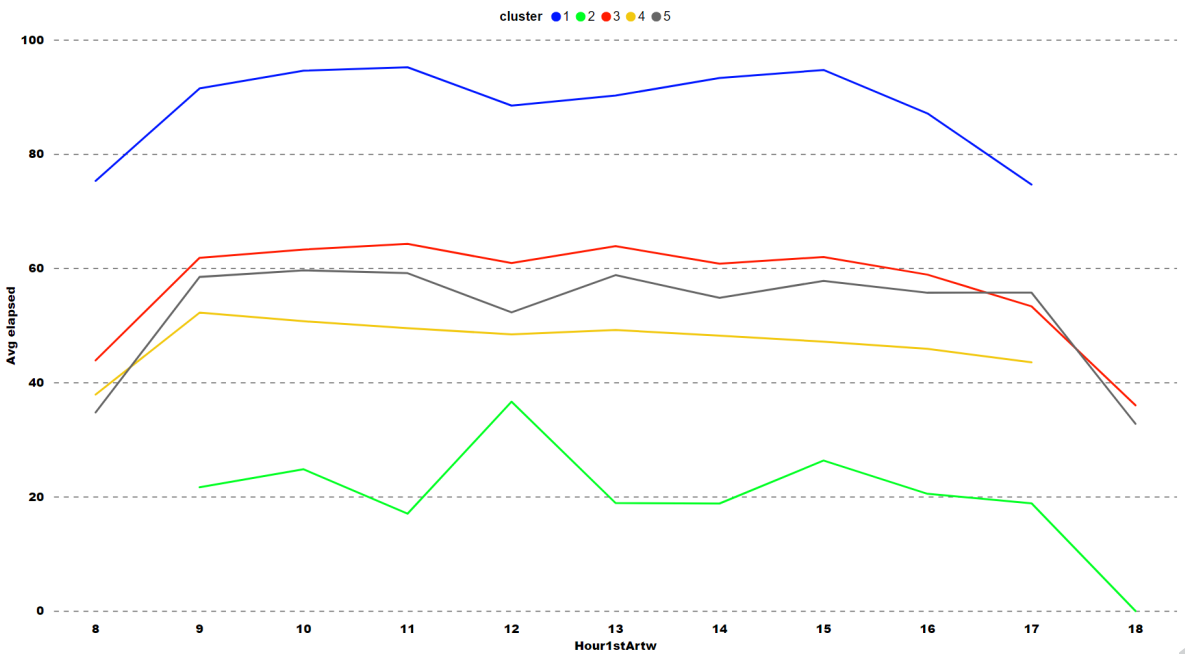

Fig. 12: The breakdown of elapsed-entry hour statistics by cluster.

In Fig. 12, for example, we report a breakdown of the entry hour vs. average elapsed relationships for each user profile; this reveals that the decrease of elapsed with entry hour follows different patterns:

- only moderate visitors (cl. 4), which account for the majority of the overall population, follow a definitely decreasing trend in elapsed since h.10:00;

- strongly engaged visitors (cl. 1) keep their averages within a range of high values, fluctuating up and down until entry hour 15 , with a remarkable decrease trend only starting from h.16:00 and after;

- runners (cl. 5) and wanderers (cl. 3) follow fluctuating patterns which appear quite similar to that of strongly engaged, but staying within far lower elapsed ranges, which keep slightly higher than those of moderates; their elapsed decreases dramatically starting a little later than others (h.17:00);

- strangers (cl. 2) have more erratic fluctuations in elapsed, staying in any case at the lowest levels.

In addition to the length of stay we studied how visitors spend their time, by examining the tablet-based interactions with artworks (T-actions). According to the cluster centroids in Table 4, the levels of artwork-related Tinteractivity (nactartw) can be combined with different levels of elapsed time, depending on the cluster; combinations of high values in both elapsed time and T-interactivity occur only in visitors of cluster 1 (strongly engaged). At the same time, we observe that clusters having increasing values of nartw (the number of distinct artworks selected) also have increasing values of nactartw (the corresponding number of actions); in particular, cluster 1 includes visitors having high values in both nartw and nactartw simultaneously. In order to obtain more insights on such behaviors, we performed drill-down to the level of individual visitors of each cluster. For example, in Fig. 13 each dot represents a 


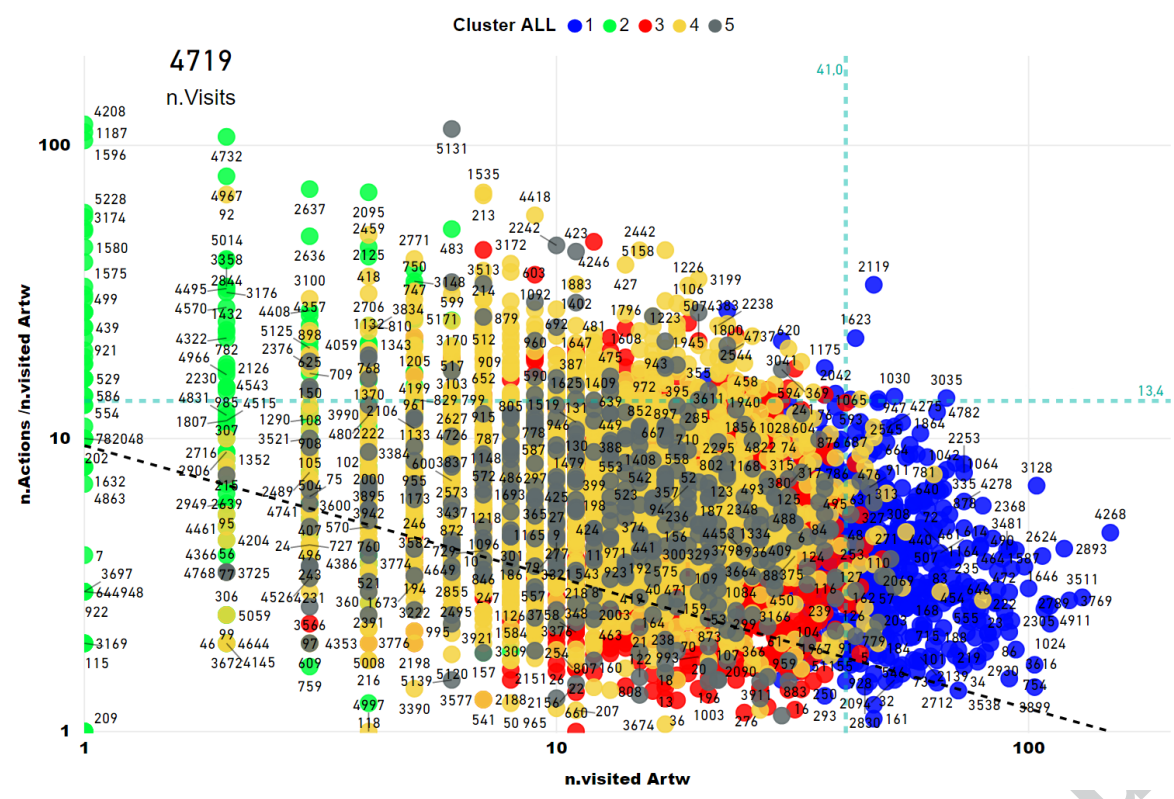

Fig. 13: The scatter diagram of individual T-interactivity ratio vs. n. of distinct artworks visited.

visitor, labelled with a unique numeric identifier, while the colour indicates the corresponding cluster. This scatter diagram reports how the T-actions/distinct artworks ratio can vary for different values of distinct artworks; logarithmic scales are used in both $\mathrm{x}$ and $\mathrm{y}$ axes, mainly due to the large range of values of nactartw. The dotted vertical and horizontal lines represent 90 th percentiles of nartw and nactartw respectively, while the sloped black line represents a statistical trend line.

Here it is evident that, although the spread of values of this ratio remains relevant among individuals, as nartw increases the corresponding nactartw/nartw ratio tends to decrease. In addition, the magnitude of the spread of values is also different among clusters, and tends to diminish for clusters with higher levels of engagement, particularly in cluster 1 . This means that strongly engaged visitors, for visiting many more distinct artworks than others, also perform many more T-actions in total, but it is very unlikely that they perform too many actions related to a single artwork for all the visited artworks, otherwise this would require either extreme lengths of stay or particularly frenetic activity, which can occur for a few outliers. We remark that, at the individual visit level, a certain degree of overlap between clusters isn't a surprise, since a diagram such Fig. 13 represents a projection onto a 2D plane from a 6 -dimensional space. This is just another way to appreciate that, although investigating variables in pairs is very useful for highlighting specific trends and relationships, all or most of the 6 variables identified with the PCA remain necessary for characterizing visitor profiles. Interesting insights on the 
Table 7: The lengths of audio files expressed in minutes.

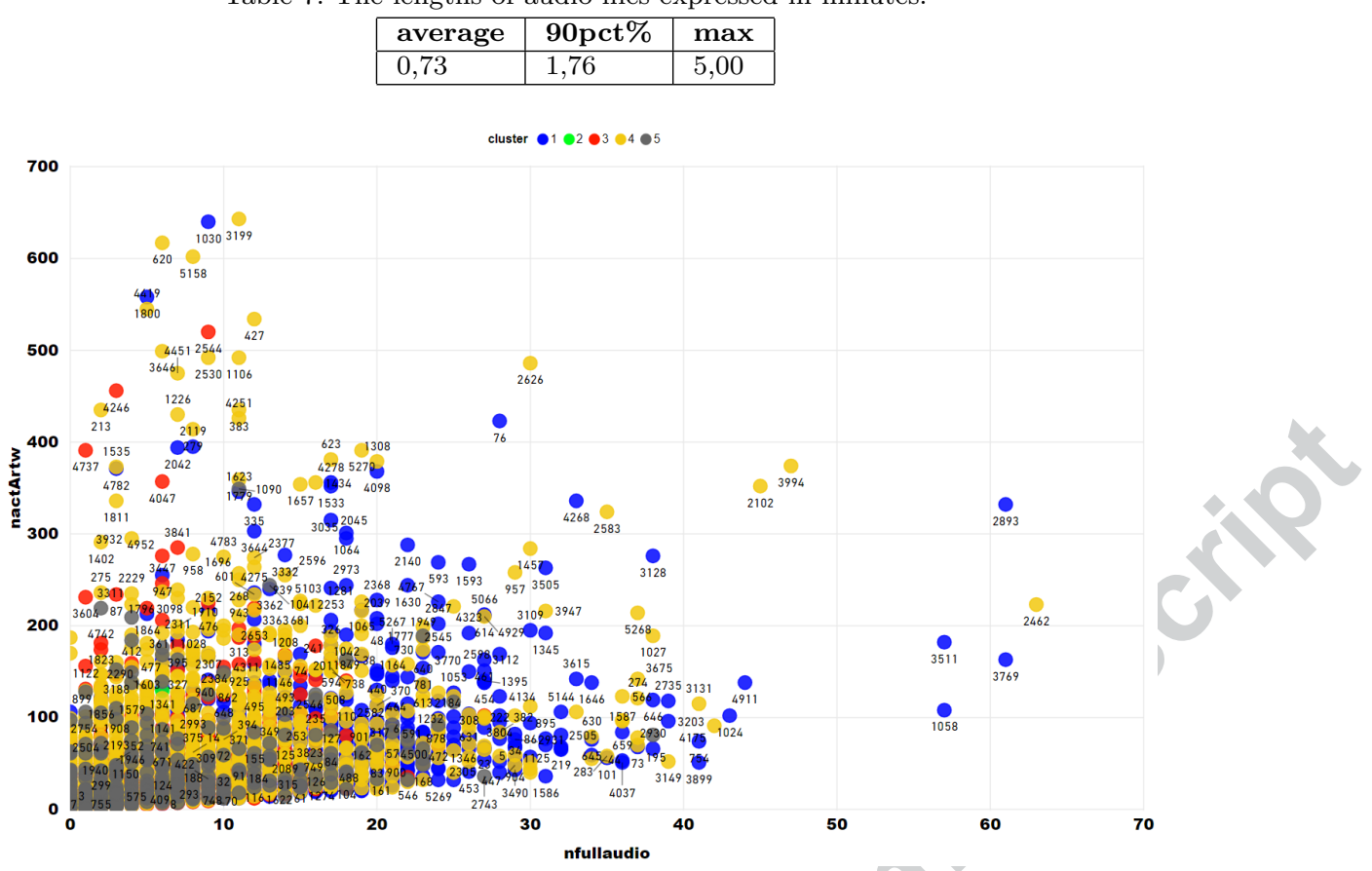

Fig. 14: The scatter diagram of photo-gallery actions vs. n.of audio files played in full.

types of activities are provided by nfullaudio, which accounts for the cases when the visitor let the audio file be played in full by the APP.

We can observe that the length of most audio tracks is comprised between 1 and 2 minutes (see Table 7), while skimming many photos requires very few seconds; hence, we could expect that high values of the nfullaudio feature characterize visitors who devote to artworks much more time than other visitors, and their total elapsed time should be higher as well. On the other hand, some visitors might find audio tracks annoying (and also consider some human guides boring as well), so that they stop audio although they still spend noticeable time for artworks, observing them visually and /or performing a relevant number of other types of artwork-related T-actions, such as photo gallery navigation and text reading. For this reason, we studied the combinations of values of nfullaudio with nactphoto (see Fig. 14).

In Fig. 14, beyond the threshold value of 35 related to the nfullaudio feature, we can observe a wide spread of combinations between the nactphoto and nfullaudio features, ranging from (nfullaudio low, nactphoto high) to (nfullaudio high, nactphoto low); beyond this threshold, the nfullaudio feature increases with minimal or no increase in nactphoto (bottom-right area of the diagram), except for some outliers. In very few cases the nactphoto feature appears dominant with respect to nfullaudio one (high-left area of the dia- 
gram), while very high values of both nfullaudio and nactphoto features can be found almost exclusively within the cluster 1 (strongly engaged visitors). These observations are consistent with the results obtained from the PCA (see Fig. 4): although visitors can play high quantities of actions on photos (thus confirming their interest on this available option), the contribution of the nactphoto feature to the 1st principal component is by far less important than the nfullaudio and nactartw features, which includes all types of actions related to artworks (artwork selection, photo and text exploration, audio slider seektrack / stop / up). One possible explanation for such results is that artworks don't speak, while the primary reason of a visit is seeing or touching them (for blind persons). Hence, audio files provide a type of experience that artworks cannot provide at all, while photos play an important but ancillary augmentation of visual experience. Photo galleries appear scanned in any visitor profile, while only people having a sufficient level of motivation tend to listen many audio files in full. This trend can be detected since the first room including a relevant number of artworks (e.g. Charles V or Picture Gallery at Level1), hence the nfullaudio feature is one of the most suitable candidates for early predictions of engagement levels during the visit.

\section{Main lessons learned}

Studying a complex cultural setting for a long period of time was essential to provide consistent support to the representativeness and reliability of findings, which can be grouped in three main areas: (i) affordability, meaningfulness and manageability of the user model, (ii) assumptions about users vs. user expectations, (iii)comparison and synergies between different systems for data collection and analysis.

\section{Affordability, meaningfulness and manageability of the user model:} In order to obtain relevant and meaningful visitor profiles, adopting an unsupervised approach entails benefits and risks, which are generally difficult to balance; in particular, this occurs in the case of k-means clustering, where the problem of selecting optimal values for $\mathrm{k}$ is combined to that of selecting a reasonable set of features having a convenient predictive power. We mitigated the risks by combining PCA for feature selection with a set of multiple mathematical indexes, and by applying them to a large data set collected in a longitudinal study, embracing many consecutive months of daily observations. We discovered that these indexes converged to the recommendation of a value for $\mathrm{k}$ (5), which also satisfied the human need for a non-trivial but limited set of visitor profiles, especially for the sake of museum stakeholders and other related cultural heritage promoters. Even the number of features (6) appeared not excessive to them, although it was necessary to carefully map the numeric values provided by $\mathrm{R}$ to suitable nominal scales for making the model easy to understand. In terms of cost, 
the proposed system appeared affordable, since it was automated by combining common statistical packages and business intelligence tools, which are easily available both on desktop and web-cloud (R, MS Power BI).

\section{Assumptions about users vs. user expectations:}

We checked the qualities of the resulting $5 \times 6$ visitor profiles matrix at different levels of detail, comparing common assumptions with many types of evidences and outcomes provided by this model. A population of people paying for both the museum ticket and an additional fee for an interactive device raised optimistic expectations about their levels of interest and performances, while our study demonstrated that these were only partially met. Although this sample represents the self-selection of visitors who pay more for having some services, we ascertained relevant diversities of behaviors inside this kind of population; in particular, the features of the proposed 5 user profiles resulted very useful to qualify and quantify these diversities, revealing that only one profile has a strong level of engagement in all aspects of the proposed user experience, as well as profile with very low performances all aspects. The other intermediate profiles have different combinations of performances in two or more aspects, which cover direct interest in artworks, interest in contextual interactions with multi-medial contents, propensity to ample movements in the physical space (i.e. interfloors), and length of stay in the museum. In the area of multi-medial assistance, on average, all kinds of multi-medial contents (images, text and audio files) have respectable frequencies of selection, while only the propensity for playing artwork-specific audio files results very relevant for discriminating among user profiles, and it is one of the most suitable candidates to be considered for early predictions on individual behaviors. Apart from this distinction, the quantity of interactions with the mobile multimedial APP has a very wide range of variability among visitors, as well as the average quantity of T-actions per single artwork, but these indicators are not directly correlated to the total elapsed time of visit: visitors of some profiles tend to spend longer times than others without increasing the quantity of T_actions. This extra time without interactions with the APP could include pure observations of artworks, pauses for other activities, or slow movements between rooms and floors which are caught by comparing nfloors to elapsed time. The poor-performance profile (strangers) could be explained by a combination of multiple factors: subjective inconsistencies between what people pay and their willingness to exploit it, inadequate awareness of the nature of the (smart) museum experience, and insufficient availability of time. Another hypothesis is the case of a large distance between the expectations of some people about the @art APP and its actual features: in principle, we cannot exclude that this kind of APP resulted not particularly exciting also for people of other profiles, producing a certain impact on their performances. 
3. Comparison and synergies between different systems for data collection and analysis:

In order to check the above assumption, it is possible to integrate our system with user questionnaires, while improvements in user performances could be expected by proposing them more fascinating technologies, such as augmented reality and holograms in the museum. Even in such perspectives, the results obtained in our study can be used as a reference and well-defined term of comparison, in order to assess in which areas, and to which extent improvements will be actually achieved. In this respect, we observe that our model is suitable for comparisons with results obtained using different types of data collection and monitoring systems. In particular, we compared our results about the elapsed time of visitors with a study on the length of stay in a very complex and outstanding museum (the Louvre), based on the noninvasive monitoring of personal bluetooth devices of visitors [14]. In particular, we ascertained that the time spent for interacting with an APP such as @art can influence the absolute values of the total length of stay, whose range also depends on many characteristics of the specific museum (size, quantity of attractions, means and routes for physical movements, etc.), but we found that some patterns are very similar in both scenarios. In particular, our study confirms that the lengths of stay tend to decrease toward the closing hours of the museum, as well as that the earlier a visitor enters the museum, the longer that visitor tends to stay in the museum. On the other hand, the rates of decrease starting from early entry times towards late entry times are different in the two studies, and the breakdown of diagrams at cluster level shows that different user profiles have significant differences in multiple aspects: the ranges of length of stay, the slope of the lines, the presence and magnitude of up and down fluctuations. This level of detail on elapsed time was obtained thanks to the functionalities of our interactive APP, which was also indispensable for investigating how visitors spend their time. For the sake of monitoring, we realized that non-invasive systems and interactive systems should not be treated as mutually exclusive, but rather used in synergic ways. A non-invasive system based on widespread personal devices catches many visitors who dont rent any device offered by the museum, and has no impact on their behaviors. An interactive system provided by the museum is conceived for impacting the behaviors of visitors by purpose, but mainly in terms of quality of experience rather than quantity; it catches visitors which are attracted by mobile interactive facilities, although the actual motivation and levels of engagement may be very variable among individuals. A certain area of overlap exists between these two systems, in that an interactive system can check and confirm some types of patterns observed with a non-invasive system, while providing more insights and added value on more aspects of visitor behaviors. In the perspective of a multi-technology, synergic approach, we remark that the proposed 6-dimensional model is both inclusive and flexible, since it includes the features that can be mon- 
itored using non-invasive systems as well other features which are typical of interactive systems.

\section{Conclusions and Future work}

We experimented a totally unsupervised approach for obtaining visitor profiles from a numerous population of visitors in a wide period of time, which is not influenced by the characteristics of pre-conceived models coming from sociological theories or other qualitative empirical observations. The proposed system has the capability to identify and quantify a limited but significant number of different visitor profiles, which can be the targets of distinct strategies and specific programs for improvement, evolution and promotion of museum experiences. The noticeable variability of some features of individual behaviors, which we observed also inside each cluster, can also be seen as a source of opportunities, since it allows to estimate that some individuals within a profile could easily switch to another more performant profile, in response to new proposals or well focused improvements and evolutions of existing ones. For such purposes, museum stakeholders can consider different kinds of initiatives: hosting new types of artistic installations and new kinds of exhibitions at the museum premises; opening new rooms to visitors; changes in the disposition of artworks; improvements in the facilities for visitors movements, provision of internet connectivity, and advances in technological devices for enriching the visitor knowledge and interactions with artworks. One promising road is the evolution of APPs for offering more and more personalized recommendation during the visit. However, the objective should not be to maximize interactions with all sorts of technological devices for each second of entire visit, otherwise physical visits to museum premises could be entirely substituted by remote virtual ones. Should brick and mortar museums continue to exist, technology must never overwhelm artworks. Future works will be focused on (i) improving the $\mathrm{k}$ selection strategy, (ii) classifying the visitors behaviour considering their physical movements/path within the space.

Acknowledgements This work was supported by the OPS-REMIAM project [grant number PON03PE_00161] and the Cultural Equipment with Transmedial Recommendation Analytics - C.E.T.R.A. project [Regione Campania - Bando RIS3 2018 - Fase 2 - Supporto di progetti, anche collaborativi, di sviluppo precompetitivo, trasferimento tecnologico da parte delle MPMI campane]

Informed consent: Informed consent was obtained from all individual participants included in the study.

The authors declare that there is no conflict of interest.

\section{References}

1. A. Bollo, Il monitoraggio e la valutazione dei pubblici dei musei. Gli Osservatori dei musei nellesperienza internazionale, Quaderni della Valorizzazione Nuova Serie, 2, Direzione Generale Valorizzazione-Mibact, (2016) 
2. T. Kuflik, Z. Boger, M. Zancanaro, Analysis and prediction of museum visitors behavioral pattern types, Ubiquitous Disp. Environ. Cogn. Technol., pp. 161-176 (2012).

3. A. Chianese, F.Marulli, F.Piccialli, P.Benedusi, J.E.Jung, An associative engines based approach supporting collaborative analytics in the Internet of cultural things, Future Generation Computer Systems, Vol. 66, pp. 187-198, (2017)

4. H. Abdi, L. J. Williams, Principal Component Analysis, Wires Computational Statistics, DOI: $10.1002 /$ wics.101, (2010)

5. T. Hastie, R. Tibshirani, J. Friedman, The Elements of Statistical Learning Data Mining, Springer, (2009)

6. J. M. Chambers, Software for Data Analysis: Programming with R, Springer (2008)

7. D.T. Pham, S.S. Dimov, C.D. Nguyen, Selection of K in K-means clustering, Proceedings of the Institution of Mechanical Engineers Part C Journal of Mechanical Engineering Science 1989-1996 Vol. 219(1) pp. 103-119, DOI: 10.1243/095440605X8298, (2005)

8. M. Charrad, N. Ghazzali, V. Boiteau, A. Niknafs, NbClust: An R Package for Determining the Relevant Number of Clusters in a Data Set, Journal of Statistical Software, Vol. 61(6), pp.1-36, (2014)

9. J.A. Hartigan, Clustering Algorithms, John Wiley \& Sons, (1975)

10. R.O. Duda, P.E. Hard, Pattern Classification and Scene Analysis. John Wiley \& Sons, (1973)

11. Beale E.M.L. Cluster Analysis, Scientific Control Systems, London (1969)

12. F.H.C. Marriot, Practical Problems in a Method of Cluster Analysis, Biometrics, Vol. 27(3), pp.501514, (1971)

13. A.J. Scott, M.J. Symons, Clustering Methods Based on Likelihood Ratio Criteria, Biometrics, Vol. 27(2), pp. 387397, (1971)

14. Y. Yoshimura, A. Krebs, C. Ratti, Non invasive Bluetooth Monitoring of Visitors Length of Stay at the Louvre, IEEE Pervasive Computing, Vol. 16(2) pp.26-33, (2017)

15. Weinfurt, Kevin P. Multivariate Analysis of Variance, in Reading and Understanding Multivariate Statistics, L.G. Grimm and P.R. Yarnold, eds. Washington: American Psychological Association, 1995.

16. E. Hooper-Greenhill, Studying visitors, In Macdonald, S. (ed) Companion to Museum Studies, Blackwell Publishing, Oxford, pp. 362-376, (2006)

17. , E. Veron, M. Levasseur Ethnographie de l'exposition : l'espace, le corps et le sens, Centres Georges Pompidou, (1989)

18. S. S. Yalowitz, K. Bronnenkant, Timing and Tracking: Unlocking Visitor Behavior, Visitor Studies, Vol. 12(1), pp. 47-64, (2009)

19. Mygind L., Bentsen P., Reviewing automated sensor-based visitor tracking studies: beyond traditional observational methods? Visitor Studies, Vol. 20 (2), pp. 202-217, 2017.

20. Kirchberg V., Martin T., The Museum Experience: Mapping the Experience of Fine Art Curator The Museum Journal, Vol. 55(2), pp. 169-193 , 2015

21. Rainoldi M., Neuhofer B., Joos M., Mobile Eyetracking of Museum Learning Experiences, Information and Communication Technologies in Tourism, pp. 473-485, 2018.

22. D. Dean, Museum exhibition theory and practice, London: Routledge, ISBN 978- 0203039-366, (1994)

23. Martella C., Miraglia A., Jeana Frost, Cattani M., van Steen M. Visualizing, clustering, and predicting the behavior of museum visitors

24. B. Serrel, Exhibit labels: an interpretive approach, Walnut Creek: Alta Mira Press, xv, 261 p. ISBN 07-619-9106-9, (1996)

25. B. Hillier, J. Hanson, The Social Logic of Space. Cambridge, New York: Cambridge University Press. http://dx.doi.org/10.1017/CBO9780511597237, (1984)

26. Yuji Yoshimura, Stanislav Sobolevsky, Carlo Ratti, Fabien Girardin, Juan Pablo Carrascal, Josep Blat, Roberta Sinatra, An analysis of visitors' behavior in the Louvre Museum: A study using Bluetooth data Environment and Planning B: Planning and Design, Vol. 41 (6), pp. 1113-1131, 2014.

27. B. Hillier, Space Is the Machine: A Configurational Theory of Architecture, Cambridge University Press, Cambridge, (1996)

28. B. Hillier, K. Tzortzi, Space Syntax: The Language of Museum Space, In: Macdonald, S, (ed.) A Companion to Museum Studies. Blackwell Publishing Ltd: Oxford, UK, pp. 282-301, (2006) 
29. F. Sparacino, The Museum Wearable: real-time sensor-driven understanding of visitors' nterests for personalized visually-augmented museum experiences, In Proc. of Museums and the Web, pp. 17-20, (2002)

30. F. Bohnert, I. Zukerman, S. Berkovskt, T. Baldwin, L. Sonenberg, Using interest and transition models to predict visitor locations in museums, AI Commun. Vol. 21, pp.195202, (2008)

31. M. Zancanaro,T. Kuflik, Z. Boger, D. Goren-Bar, D. Goldwasser, Analyzing museum visitors behavior patterns, In Proceedings of the 11th International Conference, on User Modeling (UM), pp.238246, (2007)

32. T. Kanda, M. Shiomi, L. Perrin, T. Nomura, H. Ishiguro, N. Hagita, Analysis of people trajectories with ubiquitous sensors in a science museum, In: IEEE international conference on robotics and automation, 2007. IEEE, pp. 48464853, (2008)

33. N. Brancati, G. Caggianese, M. Frucci, L. Gallo, P. Neroni, Touchless target selection techniques for wearable augmented reality systems, Intell. Interact. Multimedia Syst. Serv. pp.1-9, 2015

34. N. Abedi, A. Bhaskar, and E. Chung, Tracking Spatio-Temporal Movement of Human in Terms of Space Utilization Using Media-Access-Control Address Data, Applied Geography, Vol. 51, pp. 72-81, (2014)

35. Bello-Orgaz, J.J. Jung, D. Camacho, Social big data: Recent achievements and new challenges, Inf. Fusion, Vol. 28, pp. 4559, (2016)

36. K. Sookhanaphibarn, R. Thawonmas, A movement data analysis and synthesis tool for museum visitors behaviors, in: PCM 2009, in: LNCS, vol. 5879, pp. 144-154, (2009) 